\title{
Alimentary allergy and Ultrasonography: facts and fantasies
}

\author{
Raffaele Minella ${ }^{1}$, Arturo Tozzi ${ }^{2}$, Francesco Carlomagno ${ }^{1}$, Salvatore Iasevoli ${ }^{2}$, Eugenio \\ Rossi ${ }^{3}$, Rocco Minelli ${ }^{4}$, \\ 1 Primary Care Pediatrician, ASLNA3Sud, Italy \\ ${ }_{2}^{2}$ Primary Care Pediatrician, ASLNA2Nord, Italy \\ ${ }^{3}$ Department of Radiology, "Santobono-Pausilipon" Children Hospital, Naples, Italy \\ ${ }^{4}$ Department of Life and Health "V. Tiberio", University of Molise, Italy \\ Corresponding Author: Raffaele Minella, PHD, email: raffaele-minella@libero.it
}

\begin{abstract}
:
The internationals guidelines about food intolerances, allergy and immunity provide for rigorous steps in which ultrasonography is not provided. However there is evidence in literature about an ancillar role of ultrasonography in these conditions.

In this report we analyze the main pathologies with allergic or immune pathogenesis
\end{abstract}

Key words: Ultrasound - food allergy- Intollerance -

\section{Introduction:}

Ultrasonography (US) represents the first-choice diagnostic tool in the setting of the most relevant abdominal pathologies, however his role remain unclair and controversial in the diagnosis of allergic or immunologic disorders of the gastrointestinal tract. In fact, it is difficult to imagine how a morphological investigation could be of help in functional disorders.

However in the literature there are numerous studies that highlight a role, albeit ancillar, to US in the evaluation of these disorders. In this review we analyze the ultrasound findings of the main pathologies food-related

Hypertrophic pyloric stenosis.

The hypertrophic pyloric stenosis (HPS) is a condition characterized by progressive hypertrophy of the smooth muscle of the pylorus. This hypertrophy leads to worsening vomiting with 
metabolic alkalosis and dehydration with the need for surgery. The US scan play a relevant role in the diagnosis of HPS: diagnostic criteria for PS included muscle thickness equal to or greater than 4 $\mathrm{mm}$, length equal to or greater than $18 \mathrm{~mm}$, and/or limited flow of fluid through the pyloric channel (Fig 1)(1). Us was performed with patient in supine position or in oblique right position, by mean of a linear 7,5-12 MHz probe. US had a 100\% sensitivity and $100 \%$ specificity for HPS: thickness of $3 \mathrm{~mm}$ or higher was 100\% sensitive and 99\% specific for HPS, and pyloric lenght of 15 $\mathrm{mm}$ or higher was $100 \%$ sensitive and $97 \%$ specific (2). Another signs is increased vascularity at color-Doppler examination (3).

However, some conditions mimic hypertrophic stenosis: since 1972 a correlation between HPS and allergy has been hypothesized (4) and in 1978 another report was reported (5). A case of foveole hyperplasia presenting with clinical symptoms of HPS has been reported (6). Indeed there is a recent report about eosinophilic gastroenteritis mimicking HPS (7). The eosinophilic gastroenteritis is part of the pathologies in which food awareness can be demonstrated. As a final consideration we report a study in which authors observe the high incidence of HPS in patients undergoing gastrointestinal surgery (8): HPS: cause or effect of allergy?

\section{Cow's milk allergy:}

Cow's milk protein (CMP) allergy is a condition frequently encountered in the first 36 months of life and $2-3 \%$ of children are believed to have this condition (9). The diagnosis is based on clinical criteria, remission of symptoms on a milk protein-free diet and recovery of symptoms with the reintroduction of milk proteins (10). Numerous studies have been conducted regarding the correlation between allergy and US $(11,12,13)$. The patient was in supine position, and examination was performed by mean of 7,5 -12 MHz probe. The following parameters were considered: wall thickness of ileum and colon, defined as normal if the thicknesses is higher of 3 
$\mathrm{mm}$ and $4 \mathrm{~mm}$, rispectively. The thickness was measured by placing the pointer between the mucosal surface and the serosa in the same bowel loop. Another sign considered is vessel density, evaluated at color-Doppler examination. In conclusion Doppler ultrasonography and small intestinal vessel density can support the diagnosis of CMP allergy. Promising studies are underway similar to those conducted on upper mesenteric artery flowmetry in patients with celiac disease.

Interesting studies between allergy and liver involvement have been conducted: the main role seems to be played by mast cells, a common point between the allergic cascade and that of NAFLD $(14,15,16,17)$

\section{Coeliac disease}

The celiac disease is a peculiar intolerance to gluten, a protein widely spread in food, especially in wheat. The symptoms are related to malasorbption, and US signs respect the pathophisiology ot the disease: intestinal loops stretched out by liquids, flattening of the mucosa and reduced wall thickness (18). Flowmeter changes are reported as expression of parietal inflammation, reversible after the introduction of a gluten-free diet $(19,20)$

\section{Conclusion:}

The US takes an emerging role in the diagnosis of food allergy-based diseases in the child and supports the clinician in the diagnosis, but further studies are needed to improve the diagnostic margins.

\section{Conflict of interest}

The Authors declare that they have no conflict of interest 


\section{Informed consent:}

All procedures followed were in accordance with the ethical standards of the responsible committee on human experimentation (institutional and national) and with the Helsinki decalration of 1975, and its late amandments. Additional informed consented was obtained from all patients for which indentifyng information is not included in this article

\section{Human and animal rights}

This article does not contain any studies with human or animal subjects performed by any of the Authors

\section{References:}

1) Hernanz-Schulman M. (2009). Pyloric stenosis: role of imaging. Pediatr Radiol 39:5134-5139

2) Iqbal CW, Rivald DC, Mortellaro VE, Sharp SW, Peter SD, (2012). Evaluation of

ultrasonographic parameters in the diagnosis of hypertropic pyloric stenosis relative to patient and age. J Surg 47:1542-1547

3) Hernanz-Schulman M, Zu Y, Stein SM, Heller RM, Bethel LA (2003). Hypertrophyc pyloric stenosis in infant: ultrasonographic evaluation of vascularity of the pyloric canal. Radiology 229:389-393

4) Collincot PE, Chapopel SJ, Bill AM (1972). Is there a correlation between allergy and infantile pyloric stenosis. Pediatrics 49:768-769

5) Venura A, Ciana G, Vinci A, Davanzo R, Giannotta A, Perini R (1987). Hypertrophic stenosis of the pylorus. Correlation with allergy to milk protein and atopy. Pediatr Med Chir 9:679-683

6) Morinville W, Bernard C, Forget S (2004). Foveolar hyperplasia secondary to cow'smilk protein hypersensitivity presenting with clinical features of pyloric stenosis. J Pediatr Surg 39:e29-e31

7) Yokohama S, Nakoata T, Nakuda T, Ikeda Y, Hara S. (2020). Neonatal eosinophilic gastroenteritis mimicking hypertrophic pyloric stenosis. Pediatr int 62:99-101 
8) El Hassani A, Michaud L, Chartier A, Penel-Cappelle D, Sfeir R, Busson R et all. (2005). Cow's milk protein allergy after neonatal intestinal surgery. Arch Pediatr 12:134-139

9) Rona RJ, Keil T, Summers C Et All. (2011) The prevalence of food allergy. J Allergy Clin Immunol ;127:594-602

10) Koletzko S, Niggemann B, Arato A, Dias JA, Heuschkel R, Husby S, et all. Diagnostic approach and management of cow's milk protein allergy in infants and children: ESPGHAN GI committee Practical Guidelines (2012) Journa nutr 55:221-229

11) Epifanio M, Spolidoro JV, bernardi Soler R, Baldisserotto M. Gray-scale and color-Doppler ultrasound findings in children with cow's milk allergy (2011). AJR;196:w817-w822

12) Patenaud Y, Bernard C, Schreiber R, Sinsky AB. Cow's milk induced allergic colitis in an exclusively breast-fed infant: diagnosed with ultrasound. (2000) Pediatr Radiol 30:379-382

13) Jimbo K, Othsuka Y, KonoT, Arai N, Kyoudo R, Hosoi Ket all. (2019). Ultrasonographic study of intestinal blood flow in infantile non-IgE-mediated gastrointestinal food allergy. Allergol internat 68:199206

14) Brown C, Haringman N, Davies C, Gore C, Hussain M, Miewli-vergani Get all. (2012).High prevalence of food sensitisation in young children with liver disease: a clue to food allergy pathogenesis? Ped Allergy and Immunol 23:770-777

15) Jarido V, Kennedy L, Hargrove L, Demieville J, Thomson J , Stephenson K et all. (2017). The emerging role of mast cells in liver disease

16) Boyle RJ, Hardikar W, Tang MLK (2005). The development of food allergy after liver transplantation. Liver transplantation 11:326-330 
17) Di Serafino M, Severino R, Gioioso M, Rossi E, Vezzali N, Pelliccia P (2020). Pediatric liver ultrasound: a pictorial essay. J Ultrasound 23:87-103

18) Dietrich CF, Hollerweger A, Dirks K, Higginson A, Serra C, Calabrese $M$ et all (2019). EFSUMB Gastrointestinal ultrasound (GIUS) task force group celiac sprue and other rare gastrointestinal features. Med ultrason 3:299-315

19) Magalotti D, Volta U, Bonfiglioli A, Ramili S, berzigotti A (2003). Splanchnic haemodinamics in patients with coeliac disease: effetct of a gluten free-diet. Dig Liver Disn35:262-268

20) Ertem D, Tunei D, Baloglu H, Rehlivanoglu E (1998). Superior mesenteric artery blood flow in children with celiac disease. J pediatr gastroenterol nutr 26:140-145 